\title{
How to approach and implement strategic outsourcing programme in a global context - case study of Danish industrial enterprise
}

J. Momme and H.H. Hvolby

Department of Production, Aalborg University

Fibigerstraede 16, 9220 Aalborg Oest, Denmark

Tel: +4596358939

Fax: +4598153030

e-mail:i9jmo@iprod.auc.dk andi9hhh@iprod.auc.dk

\begin{abstract}
The paper takes its starting point in a longitudinal case study of Aalborg Industries - a large Danish industrial enterprise. Focus is on Aalborg Industries' Strategic Outsourcing Programme, which is under construction and to be implemented in the entire organisation during 1999-2000. First, the overall ideas and contents of the programme are explained. Secondly, the strategic implications and challenges of implementing the programme in three business units situated in USA, Brasil, and Denmark and characterised by three different stages of development are highlighted. In conclusion, different software applications to facilitate the integration of primary suppliers into the Aalborg Industries global network are proposed. In order to substantiate the topicality of the empirical investigations, the paper compares the globalisation process faced by Aalborg Industries with related findings in key articles.
\end{abstract}

\section{Keywords}

Globalisation, outsourcing, core competence, interorganisational competence development, integrated software applications

\section{INITIAL CONDITIONS AND PROBLEMS}

Through article reviews it has become evident that an increasing number of companies - both domestic and international - are using strategic outsourcing to 
achieve their savings and profitability objectives (Anderson and Katz, 1998). At the same time, it is recognised that successful outsourcing implies more than "just" focusing on the bottom line effect, as different qualitative performance parameters such as technological level, infrastructure, employee skills, language barriers, and cultural differences often add unforeseen costs to the transaction process. Such performance gaps between company and supplier, of course, affect the way to construct the outsourcing relationship.

(Cox, 1996) provides a helpful framework for companies that want proactively - to distinguish between different contractual relationships with their suppliers. Thus, Cox develops a typology, which links what he calls "asset specificity", competencies, and supplier relationships in order to reduce the "real costs" of transactions and improve profitability. This implies that the company must determine how close the outsourced components are to the core competencies embedded in its organisation and develop its relationships based on this knowledge. Cox's point is that the closer the outsourced components are to the strategic core of the company, the closer relationships should be established. The different supplier relationships discussed in (Cox, 1996) span arms' length relationships to whom only residual competencies are outsourced and a group covering preferred suppliers, single sourcing, network sourcing, and strategic alliances to whom complementary competencies are outsourced

Cox's approach coincides with that presented in (Venkatesan, 1992) where it is emphasised that the company must: (1) Focus on those components that are critical to the product and that the company is distinctively good at making; (2) Outsource components where suppliers have a distinct comparative advantage, i.e. greater scale, fundamentally lower cost structure, or stronger performance incentives; and (3) Use outsourcing proactively as a way to generate employee commitment and consequently improve manufacturing performance.

\section{BACKGROUND AND OBJECTIVES}

Aalborg Industries A/S (AI) was founded in 1912 and is now an international group of companies engaged in energy, steam, and heat generation for land-based as well as maritime purposes. The product range spans boilers, heaters, and inert gas systems. AI is a large company compared to the Danish industry structure with production facilities in China, Brasil, Indonesia, and Denmark and other major business units in USA, Japan, and Finland. The company employs about 1750 people worldwide. The AI Group is in the middle of a globalisation process with the intent to become more productive, more decisive, and more responsive to new opportunities. The globalisation process should be seen as a consequence of intensified global competition and increased customer needs, which has forced the company to re-examine every aspect of its business operations. Outsourcing to a global integrated supplier network, focusing on core competencies, and continuous improvement of capabilities play an essential role in this strategic planning process. 
To meet the above-mentioned challenges, a Global Product Supply function (GPS) was established in 1998, overall responsible for managing and co-ordinating three main functional areas: (1) Outsourcing; (2) Logistics/Production; and (3) Purchase. GPS must contribute to ensuring that customer commitments are met and that all AI units are recognised as high-quality, low-cost suppliers. Meeting customer commitments requires that $\mathrm{AI}$ receives the same level of commitment from its own suppliers. Thus, the complementary competencies and capabilities of the suppliers are key to AI's brand image. To support GPS in setting a proper direction of AI's global outsourcing activities, a Strategic Outsourcing Programme is under construction and to be implemented in the entire organisation during 1999-2000. The programme intends to exploit the optimum combination of AI production facilities and primary supplier relationships, thereby providing low-cost products in compliance with specific contract requirements and market needs in general.

The paper aims to outline fundamental problems and challenges, which AI faces when outsourcing to its global network of suppliers. AI's business units in USA, Brasil, and Denmark are chosen for comparative analysis because they all operate within the industrial market for land-based boilers and energy plants and presently represent three different stages of development with regard to how they control and co-ordinate their supplier base. To support the comparative analysis, the supplier relationships model developed in (Cox, 1996) is adapted to fit AI purposes. This makes allowance for using the model as a theoretical framework to position each of the three business units subjected to investigation.

\section{STRATEGIC OUTSOURCING PROGRAMME}

The Strategic Outsourcing Programme (SOP) is the tool to ensure that AI can identify, evaluate, and select those suppliers best qualified to support the company in meeting its customers' needs. The basic idea of SOP is to provide the project teams with established guidelines that allow them to effectively monitor, control, and co-ordinate the suppliers. SOP is designed to encourage long-term relationships with primary suppliers through high-class performance, interorganisational competence development, commitment, and mutual respect, while keeping an arms' length distance to secondary suppliers. The suppliers' performance is reviewed regularly to ensure that they continually meet AI demands and customer expectations. Basically, SOP is divided into four phases: (1) Identification and preliminary assessment of potential suppliers; (2) Detailed audit to establish and verify if the potential suppliers can be approved for providing products or services to AI; (3) Specific contract execution process; and (4) Performance evaluation (continuous improvement). The motivation for implementing SOP is that AI, its customers, and the suppliers will benefit in a number of ways. The most obvious benefits are: (1) High-quality products; (2) Reduced costs; (3) Improved cycle times; and (4) A flexible response to each customer's unique needs. 


\section{METHODS AND STATUS}

The full-scale advantages of SOP can only be achieved through proper planning, methodology, resource allocation (both human and finance), and employee commitment at all levels in the organisation. And still the success of SOP is influenced by cultural boundaries, political clash of interests, budget limitations, project deadlines, fear of change among employees, etc. that are always found within a global organisation like AI's and are difficult to control. In order to anticipate these "unknowns", however, semi-structured interviews are carried out with key AI employees, who represent all functional areas of relevance for elaborating SOP. These areas include Sales Support, Engineering, Purchase, Production, and Finance. In addition, data collection sheets are developed and sent out to the key employees in order to receive more detailed and structured feedback on the contents of SOP. This should ensure that the final SOP reaches a broad target group covering the global needs. Finally, visits to the business units in China, Brasil, and USA have been performed during 1998 to visually survey the production facilities, technological level, employee skills, company culture, etc. as well as to facilitate the collection of empirical data.

\section{CASE STUDY}

As the theoretical frame of reference for introducing the three cases an adapted model of Cox's typology for supplier relationships is introduced (see Figure 1). The AI Group as a whole does not differentiate the collaboration with its supplier base to the same extent as implied in Cox's model. The company can be said to employ "single sourcing" for primary suppliers of critical assemblies, but is heading for "network sourcing" with the long-term ambition to establish "strategic alliances", thereby reducing transaction cost and facilitating interorganisational competence development. For secondary suppliers of components, sheet material, etc. AI employs "adversarial leverage". This differentiation implies that the primary suppliers are targeted through SOP with special reference to establishing long-term relationships of strategic importance, while the secondary suppliers are to a certain extent played off against each other to obtain price reductions and flexibility. It also implies that in the coming years primary suppliers of major deliveries will be approached by the Outsourcing function of GPS, whereas minor primary suppliers and secondary suppliers will be maintained by the Purchase functions in the local units through co-ordination with GPS. Finally, Cox's model is consistent with AI's Strategy 1998-2002 that gives high priority to merger \& acquisitions within the strategy period to strengthen the company's position in the world market. 


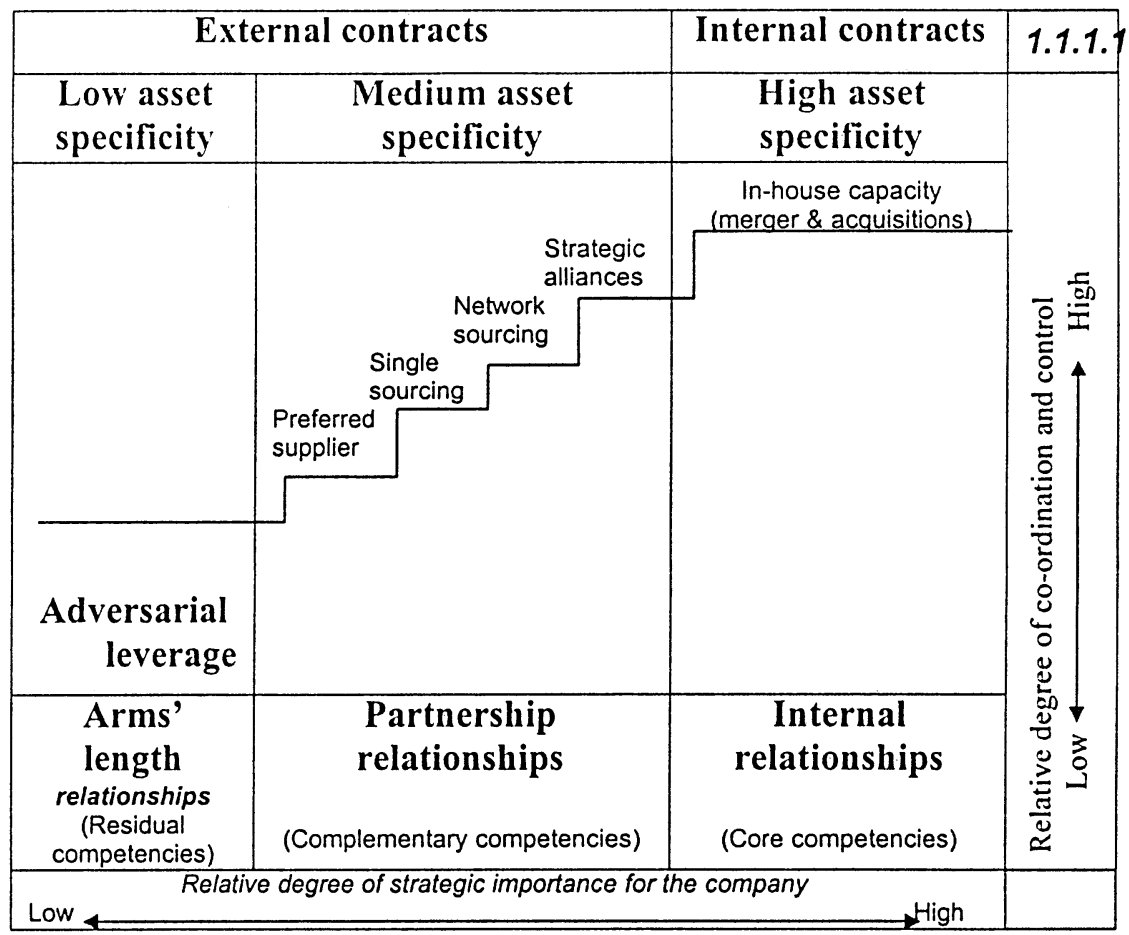

Figure 1 A step-ladder typology of external and internal contractual relationships. Adapted from (Cox, 1996, p. 63).

The adaptation of Cox's model implies that the scale of "Relative degree of strategic importance for the company" has been extended to embrace both the external and internal contracts of a firm. In addition, the scale of "Relative degree of co-ordination and control" has been added to the model.

\section{Aalborg Industries, USA (ERI)}

The American subsidiary (ERI) - located in Erie, Pennsylvania - was taken over by the AI Group in 1997. The core business areas of the company are gas/diesel turbines, gas/oil boilers, and after sales service. These products and services are sold to the primary markets in North America, South America, the Middle East, and Asia. In 1994 the ERI board at that time made the strategic decision to close down manufacturing facilities after 155 years of in-house production. This radical initiative implies that ERI from an in-house point of view now attends mainly to engineering, purchase, marketing, and sale, while functioning as a "networked organisation" within the production and transportation area. Thus, all production tasks have been outsourced to an integrated supplier network that consists of 
external independent suppliers and to a lesser extent the internal AI production units in Denmark, Brasil, and Indonesia. Eight external suppliers deliver critical assemblies with geographical locations in North America and the Far East. Designated internal project managers are responsible for co-ordinating the projects between in-house functions and the supplier network till installation and testing have taken place on the customer sites.

By using the integrated supplier network to manufacture and deliver the products to the end customer, the Purchasing function of ERI has changed from supporting goods and services for in-house manufacturing to supporting total component/material outsourcing. This means that the Purchasing function now plays a more central role in the ERI organisation in the sense that the purchasing scope of activities has been expanded to include global sourcing and product supply. ERI uses relational databases to keep track of potential and approved suppliers. The five-year experience in managing and co-ordinating the supplier network as well as the in-house software applications to support the integration process makes ERI the most competent outsourcing company within the AI Group. It is therefore only natural that the development and implementation of SOP are to a great extent based on input from the American subsidiary.

\section{Aalborg Industries, Denmark (AAL-P)}

The Danish production company (AAL-P) located in Aalborg has its roots back to the AI foundation in 1912 and therefore - like ERI - holds a long tradition with the boiler craftsmanship. As an opposing extreme to ERI, however, AAL-P up to now has been a sole in-house manufacturer with both maritime and land-based boilers included in its product line. This implies that AAL-P from an operational point of view is directly linked to the Marine Division and Land Division in Aalborg, which attend to the other key functions engineering, purchase, marketing, and sale. Again, these functions are co-ordinated through project managers. The Marine and Land Divisions independent of each other use a software module for their component purchases at secondary suppliers, and thus there is no joint supplier database across these divisions. Similarly, there is not presently an established database for potential outsourcing partners.

The fact that AAL-P manufactures both marine and land-based boilers hinders its ability to obtain an optimum production flow and a steady capacity utilisation. The main reason for this is that the lead-time of stationary plants is much longer than that of plants for marine purposes, which puts heavy demands on the production planning since both types of boilers are manufactured in the same factories. This situation combined with an increased pressure from competitors in Eastern Europe and the Far East regarding cost prices has forced AAL-P to consider strategic sourcing as an alternative way of providing complementary manufacturing competencies and capabilities. As a support to this shift in strategic focus key Aalborg employees are receiving in-house training in the four phases of SOP. The 
procedural and process knowledge gained from this training as well as the sourcing decisions already made makes AAL-P the second-most experienced outsourcing company of the tree cases presented in this paper.

\section{Aalborg Industries, Brasil (ITU)}

The Brasilian subsidiary (ITU) - located in Itu nearby São Paulo - was established as a joint venture company in 1996. ITU manufactures land-based boilers and heaters that are sold only to the Brasilian market. The production is supported by in-house purchase and engineering. The globalisation process within the Group implies that ITU is preparing for a more active role in AI's global product supply structure. The intention is that ITU - in co-ordinated collaboration with GPS expands its present scope of supply to include the South American market as a whole. In addition, the company will have to support the Group's land-based sales activities in Brasil including those products that do not form part of its core business. By exploiting the synergy contained in these actions it is the aim to develop a competitive concept that will differentiate the AI Group from its competitors on the South American market because: (1) The global know-how that exits in the individual land-based product centres forms the basis of competitive products and (2) A local company that understands how to combine in-house production with local outsourcing is used to obtain closeness to the customers and short lead-times.

In order for ITU to successfully implement the new concept, however, a paradigm shift in the organisation is called for. Two issues are of major concern in this context: (1) The company does not approach the supplier base in a systematical way as the supplier selection and collaboration procedures tend towards "local family relations" and (2) Key knowledge about the supplier base is not methodically collected and stored, primarily because no integrated software applications have been developed to support this process. This means that ITU like AAL-P - has no established database for outsourcing partners.

\section{CONCLUSION AND FUTURE WORK}

The empirical results presented in this paper point towards the need for a normative framework model that supports companies in establishing and developing supplier relationships. The paper proposes such a model emphasising that internal and external contracts should differentiate relative to the company specific value contained in the service or product provided. In the model it is implied that the strategic importance of the contracts increases with increasing relative fit of the service or product to the core competencies of the company (asset specificity). Likewise, the need for controlling and co-ordinating the relationships increases with increasing asset specificity. 
The case study of Aalborg Industries revealed, however, that the ideas behind the framework model must be supported by software applications in order to facilitate the supplier integration into the global network. These applications primarily relate to relational databases within the purchase and outsourcing area. Therefore, an integral part of the future work on adapting the Strategic Outsourcing Programme will be to develop: (1) A global item and supplier database system and (2) A global database system for potential and approved suppliers. These systems will be based on the Aalborg Industries intranet and must ensure that the individual business units are able to retrieve identical information on: (1) Prices of specific components in different countries to lower the cost structure and obtain pooled purchases and (2) Potential/approved suppliers to limit the supplier base and add more value to the suppliers' performance. In a broad perspective this exchange of value-added information on a global scale is intended to strengthen Aalborg Industries' competitiveness in terms of better quality, lower cost structure, and shortened lead-times. The Global Product Supply function is responsible for developing and implementing the new software applications.

\section{REFERENCES}

Anderson, M.G. and Katz, P.B. (1998) Strategic Sourcing, The International Journal of Logistics Management, Volume 9, No. 1, pp.1-13

Cox, A. (1996) Relational competence and strategic procurement managementTowards an entrepreneurial and contractural theory of the firm, European Journal of Purchasing \& Supply Management, Volume 2, No. 1, pp. 57-70 Venkatesan, R. (1992) Strategic Sourcing: To make or not to make, Harvard Business Review, November-December, pp. 98-107

\section{BIOGRAPHY}

Jesper Momme is industrial Ph.D. student at the Department of Production and Aalborg Industries A/S. He gained his M.Sc. degree from Aalborg University in 1997. Jesper Momme's research focuses on how to optimise the outsourcing of production tasks in the supply chain. Currently, he takes part in the development and implementation of the Strategic Outsourcing Programme at Aalborg Industries. For further details, please see http://www.iprod.auc.dk/ i9jmo/

Hans-Henrik Hvolby (M.Sc. 1984, Ph.D. 1989) works as Associate Professor at the Department of Production. His present scope of work includes production planning and control, order management, and information systems. Was employed by Aalborg Industries as planning engineer from 1984 to 1986 . Has worked at the department since 1986 with leave 1990-1992 employed by F.L. Smidth as project manager. For further details, please see http://www.iprod.auc.dk/ i9hhh/ 